\section{The prevalence of inflammatory bowel diseases, microscopic colitis, and colorectal cancer in patients with irritable bowel syndrome}

\author{
Magdy El-Salhy, 1,2 Jörg Halwe, ${ }^{1}$ \\ Bjarne Lomholt-Beck, ${ }^{3}$ \\ Doris Gundersen ${ }^{4}$
}

'Section for Gastroenterology, Department of Medicine, Stord Helse-Fonna Hospital;

2Section for Gastroenterology, Institute of Medicine, University of Bergen; ${ }^{3}$ Department of Pathology, Haugesund Helse-Fonna Hospital;

${ }^{4}$ Department of Research, Helse-Fonna, Haugesund, Norway

\section{Abstract}

The diagnosis of irritable bowel syndrome (IBS) is symptom-based and experts have developed diagnostic criteria for IBS. Distinguishing inflammatory bowel diseases (IBD) from IBS, especially with mild disease activity, can be difficult. Another concern is microscopic colitis (MC). MC and IBS have similar symptoms and a normal endoscopic appearance. Our study investigated the prevalence of patients with IBD, MC, and colorectal cancer among 968 patients that fulfill the Rome III criteria for IBS. Among these patients, four were found with IBD $(0.4 \%)$ and seven with MC (0.7\%). Among the IBD patients, three suffered from Crohn's disease, affecting the terminal ileum, and one with ulcerative rectosigmoiditis. Of the seven patients with MC, two had collagenous colitis and five had lymphocytic colitis. Two IBS diarrhea-predominant patients had adenocarcinoma in the sigmoid colon. These patients were a female aged 58 years and a male aged 56 years. We concluded from our study and earlier studies that symptom-based diagnosis of IBS may lead to missing a number of other gastrointestinal disorders that require quite different management than that for IBS.

\section{Introduction}

Irritable bowel syndrome (IBS) is a chronic condition, which is characterized by abdominal discomfort or pain, abdominal bloating, and changes in bowel habits. ${ }^{1,2}$ About 15-25\% of the world's population suffer from IBS. ${ }^{1}$ Besides the increased morbidity caused by IBS, it represents an economic burden to society in different direct and indirect forms such as increased sick leave and over-consumption of healthcare resources. ${ }^{2,3}$ There are no biologic, anatomic, or physiologic markers for IBS. ${ }^{3}$ Thus, the diagnosis is symptom-based and experts have developed criteria, such as the Rome III criteria, for the diagnosis of IBS. ${ }^{4}$ In these criteria, warning symptoms such as weight loss, rectal bleeding, and the presence of inflammatory/infection markers should be excluded. IBS patients are subgrouped, on the basis of differences in predominant bowel patterns, as: diarrhea-predominant (IBS-D), constipation-predominant (IBS-C), or a mixture of both diarrhea and constipation types (IBS-M).

Distinguishing inflammatory bowel diseases (IBD) from IBS can be difficult, especially with mild disease activity. Both conditions share a symptom complex with abdominal pain and altered bowel habits. Moreover, IBS-like symptoms are frequently reported before the diagnosis of IBD. ${ }^{5,6}$ Another concern is microscopic colitis (MC), which has similar symptoms to IBS and also a normal endoscopic appearance. ${ }^{3}$ Diagnostic overlap between IBS and IBD on one hand and IBS and MC on the other is important because of potentially different treatments for each disorder. Our study is an attempt to investigate the prevalence of patients with IBD, MC, and colorectal cancer among patients, who fulfill the Rome III criteria for IBS, referred to the gastroenterology section in our hospital in the last five years.

\section{Materials and Methods}

\section{Patients}

Patients referred to the gastroenterology section, Stord Helse-Fonna Hospital, from December 2005 to December 2010 who satisfied the Rome III criteria for the diagnosis of IBS were considered for inclusion in the study. Patients between 18 and 60 years of age who did not suffer from organic gastrointestinal disease or clinically significant system disease were included in the survey. Pregnant or lactating women were excluded. Furthermore, patients who had undergone any abdominal surgery, with the exception of appendectomy, Cesarean section, or hysterectomy, were excluded. In addition, patients with a history of psychosis or mental illness were not included. All patients underwent a complete physical examination and were investigated by blood tests including a full blood count; investigation of electrolytes, calcium, folic acid, vitamin B12, inflammatory markers; and kidney, liver, and thyroid function tests.
Correspondence: Magdy El-Salhy, Professor/ Consultant Gastroenterologist, Section for Gastroenterology, Medicine Clinic, Stord HelseFonna Hospital, Box 4000, 5409 Stord, Norway. E-mail: magdy.el-salhy@helse-fonna.no

Key words: Crohn's disease, histopathology, irritable bowel syndrome, immunocytochemistry, microscopic colitis prevalence, colorectal cancer, screening.

Acknowledgments: the authors wish to thank Ann Kristin Koppang for her enthusiasm and for assisting in and keeping up the patients' lists as well as organizing the medical records. Thanks are due to Åsa Helene Lundal at the Department of Pathology, Haugesund hospital, for co-ordinating the collaboration between Stord and Haugesund hospitals. We thank the nurses Eli Lillebø, Astrid Reinemo, and Lillian Salmelid for assisting during the colonoscopies. We would like to express our gratitude to Professor Hans Olav Fadnes, head of the Department of Medicine, Stord Helse-Fonna hospital, for his support and for reading the manuscript. This study was supported by a grant from Helse-Fonna.

Contributions: ME, planned the project, examined the patients, performed the colonoscopies on most patients, evaluated the results, and wrote the manuscript; $\mathrm{JH}$ contributed to the planning, examining of some of the patients with a colonoscopy, and writing the manuscript; BL-B, performed the histopathological examinations and participated in the planning and writing of the manuscript; DG participated in planning, evaluating of results, and writing of the manuscript.

Conflict of interest: the authors report no conflicts of interest.

Received for publication: 17 February 2011.

Revision received: 17 April 2011.

Accepted for publication: 19 April 2011.

This work is licensed under a Creative Commons Attribution 3.0 License (by-nc 3.0).

(C) Copyright M. El-Salhy et al., 2011

Licensee PAGEPress, Italy

Gastroenterology Insights 2011; 3:e3 doi:10.4081/gi.2011.e3

\section{Ileocolonoscopy}

Ileocolonoscopy was done in all patients as a routine in our hospital. Two biopsies were taken from the cecum, ascending colon, and right half of the transverse colon (the six biopsies pooled to represent the right colon), and two biopsies were taken from the left half of the transverse colon, descending colon, and sigmoid colon (pooled to represent the left colon). Three to four biopsies were also taken from the ileum, and from pathological findings that were observed. Biopsies were fixed in $4 \%$ buffered paraformaldehyde overnight, embedded in paraffin wax, and cut into $5 \mu \mathrm{m}$ thick sections. 


\section{Histopathology and immunohisto- chemistry}

The sections were stained with hematoxylin-eosin and immunostained with the avidin-biotin complex (ABC) method, using the Vectastain ABC-kit (Vector Laboratories) as described in detail earlier. ${ }^{7}$ The primary antibodies used were: monoclonal mouse antihuman leukocytes CD45 (DakoCytomation, code no. IS751) and monoclonal antibodies to collagen type III (Acris, code no P02461). The second layer of biotinylated mouse anti-IgG were obtained from DakoCytomation, Denmark. The stained and immunostained sections were examined for the possible occurrence of MC.

The diagnosis of lymphocytic colitis required an increase in intraepithelial lymphocytes (>15 lymphocytes/100 epithelial cells) and surface epithelial damage, with increased lamnia propria plasma cells and absent or min- imal crypt architectural distribution. For the diagnosis of collagenous colitis, an increase or irregularity in subepithelial collagen $(>10$ $\mu \mathrm{m})$ that trapped superficial capillaries was required as well as the other inflammatory changes seen in lymphocytic colitis. ${ }^{8}$

\section{Results}

\section{Patients}

The study included a total of 968 patients with an average age of 32 years (range 18-59 years). Females made up $95 \%$ of all patients. Of the patients, $45 \%$ were IBS-D, $30 \%$ IBS-M, and 25\% IBS-C (Tables 1 and 2).

\section{Ileocolonoscopy}

The ileum, colon, and rectum of all patients were macroscopically normal, except in four
IBS-D patients who showed mucosal lesions. The first three had scattered aphthoid ulcers in otherwise normal mucosa of the terminal ileum. The fourth patient had diffusely erythematous, friable, and granular mucosa with the loss of the normal vascular pattern, extending for $10 \mathrm{~cm}$ of the sigmoid colon and including the whole rectum (Figure 1). These patients were three females and one male aged $32,59,35$, and 57 years, respectively. This amounts to a prevalence of $0.4 \%$ of IBD in patients with IBS. Two IBS-D patients each showed a tumor in the sigmoid colon, from where biopsies were taken. These patients were a female aged 58 and a male aged 56 years.

\section{Histopathology and immunohisto- chemistry}

Histopathological examination showed that the four patients with mucosal lesions

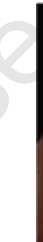

Table 2. Data of irritable bowel syndrome-diarrhea patients, who have been found to suffer from an organic disease.

\begin{tabular}{|c|c|c|c|c|c|c|}
\hline & Total & $\begin{array}{l}\text { Crohn's } \\
\text { disease }\end{array}$ & $\begin{array}{c}\text { Ulcerative } \\
\text { colitis }\end{array}$ & $\begin{array}{c}\text { Collagenous } \\
\text { colitis }\end{array}$ & $\begin{array}{l}\text { Lymphocytic } \\
\text { colitis }\end{array}$ & Cancer \\
\hline Number & 436 & 3 & 1 & 2 & 5 & 2 \\
\hline Age (years) & $20-59$ & 32,59 & 57 & 36,42 & $24,27,35,36,42$ & 56,58 \\
\hline $\begin{array}{l}\text { Sex } \\
\text { (females/males) }\end{array}$ & $409 / 27$ & All females & Female & All females & $4 / 1$ & $1 / 1$ \\
\hline Localization & & $\begin{array}{l}\text { Terminal } \\
\text { ileum }\end{array}$ & $\begin{array}{l}\text { Rectosigmoid } \\
\text { colon }\end{array}$ & Colon & Colon & $\begin{array}{l}\text { Sigmoid } \\
\text { colon }\end{array}$ \\
\hline $\begin{array}{l}\text { B-hemoglobin* } \\
\text { (13.3-17) }\end{array}$ & $13.3-17$ & $13.4,14,13.5$ & 15 & 14,15 & $13.3,14,13.5,15,14.8$ & 16,15 \\
\hline $\begin{array}{l}\text { B-MCV } \\
(82-98)\end{array}$ & $82-95$ & $85,87,90$ & 92 & 88,89 & $84,83,82,88,90$ & 85,92 \\
\hline $\begin{array}{l}\text { B-leukocytes } \\
(3.5-8.8)\end{array}$ & $3.9-6.1$ & $3.5,4.5,3.9$ & 7 & $4,5.8$ & $3.9,5.7,8.5,3.8,7.9$ & $3.6,4.8$ \\
\hline $\begin{array}{l}\text { B-trombocytes } \\
(145-348)\end{array}$ & $150-320$ & $179,186,279$ & 320 & 246,300 & $202,254,305,287,235$ & 306,310 \\
\hline $\begin{array}{l}\text { S-ferritin } \\
(30-400)\end{array}$ & $30-400$ & $30,39,120$ & 49 & 39,59 & $32,45,67,98,150$ & 390,400 \\
\hline $\begin{array}{l}\text { S-free T4 thyroxin } \\
(12-22)\end{array}$ & $14-20$ & $14,19,18$ & 20 & 15,18 & $16,20,18,17,14$ & 20,16 \\
\hline $\begin{array}{l}\text { S-TSH } \\
(0.27-4.2)\end{array}$ & $0.3-4$ & $0.5,3,1.5$ & 0.3 & $3,3.5$ & $2,0.8,0.0 .9,3,4$ & $4,0.8$ \\
\hline S-CRP $(<5)$ & $1-4$ & $1,1.5,2$ & 2 & $3,2.2$ & $1,4,3,2.9,2.3$ & 3,4 \\
\hline $\begin{array}{l}\text { S-creatinin } \\
(60-100)\end{array}$ & $60-92$ & $65,63,71$ & 87 & 68,73 & $60,68,81,67,68$ & 92,90 \\
\hline $\begin{array}{l}\text { S-albumin } \\
(36-48)\end{array}$ & $36-48$ & 36,37 & 38 & 40,44 & $36,36,39,40,42$ & 48,47 \\
\hline
\end{tabular}

All had normal electrolytes, normal S-bilirubin, S-ASAT, SALAT, and S-glucose; *normal values.

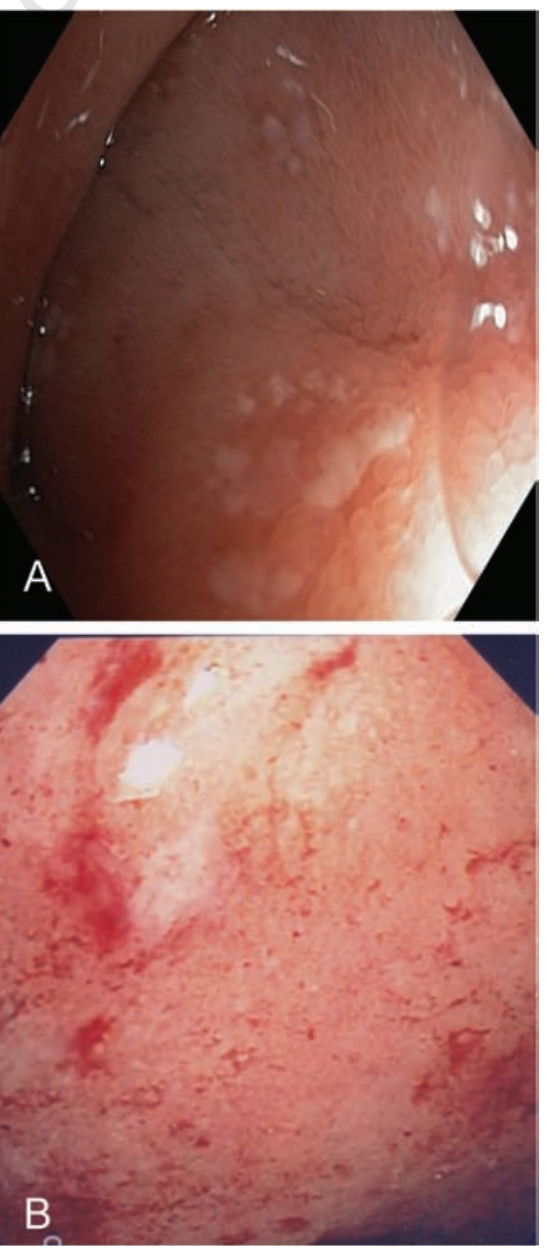

Figure 1. Endoscopic appearance of the terminal ileum with aphthoid ulcers in a 32-year-old female (A), and in the sigmoid colon of a 57-year-old female (B). Both fulfill the Rome III criteria for irritable bowel syndrome. 
revealed Crohn's disease in three patients and ulcerative rectosigmoiditis in the fourth. Furthermore, seven IBD-D patients showed MC: two with collagenous and five with lymphocytic colitis (Figures 2 and 3). The two patients with collagenous colitis were females aged 36 and 42 years; those with lymphocytic
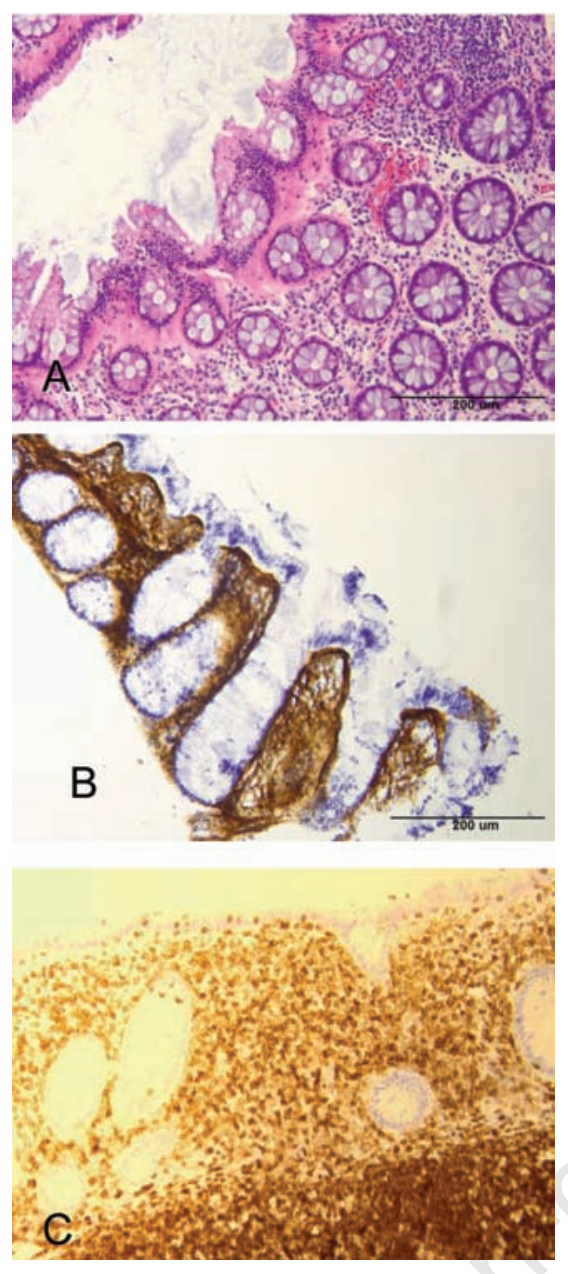

Figure 2. Photomicrographs of the colon of a 36-year-old female who fulfills the Rome III criteria for irritable bowel syndrome. Sections are stained with hematoxylin and eosin (A), for collagen III (B), and for CD45 (C).

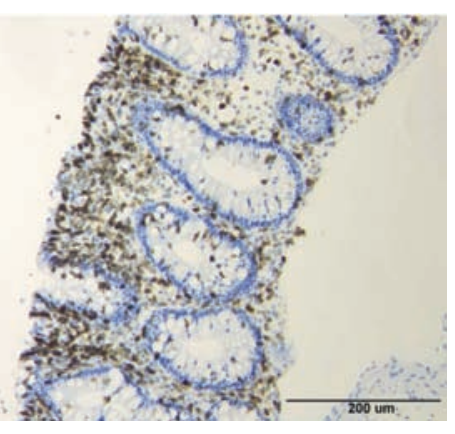

Figure 3. Lymphocytic colitis in a colonic section immunostained for CD45 in a 24year-old female. This patient fulfills the Rome III criteria. colitis were four females and one male, aged $24,27,35,36$, and 42 years. Thus, the prevalence of MC in IBS patients was $0.7 \%$. The histopathological examination in the two IBSD patients with a sigmoid tumor confirmed the diagnosis of adenocarcinoma.

\section{Discussion}

Our study represents the largest evaluation of the diagnostic outcome of ileocolonoscopy and mucosal biopsies in patients with all subtypes of IBS, namely, IBS-D, IBS-M, and IBS-C. Furthermore, our study concentrated on the clinically relevant diagnoses, which call upon treatment measures other than those offered for IBS patients. Thus, IBD, MC, and colorectal cancer were considered. Other harmless structural lesions were not accounted for.

Several gastroenterologists believe that a symptom-based diagnosis, such as that based on the Rome III criteria, without warning symptoms is enough for the diagnosis of IBS and no further investigations are needed. The American College of Gastroenterology Task Force does not recommend routine colonic imaging in patients younger than 50 years of age without alarm features and colonoscopic imaging should be reserved for those over the age of 50 years for the purpose of cancer screening. ${ }^{9}$ In our study, two patients had had carcinoma of the colon. Both of them were over 50 years old. Thus, this recommendation seems to be suitable for detecting and diagnosing colorectal cancer in this group of patients. Actually, colorectal cancer is the diagnosis that patients fear the most and physicians are concerned to miss. In a previous study on 196 subjects with suspected IBS, one patient with colon carcinoma was found, amounting to a prevalence of $0.5 \%{ }^{10}$

Our study showed that $0.4 \%$ and $0.7 \%$ of patients that fulfilled the Rome III criteria without alarm symptoms suffered from IBD and $\mathrm{MC}$, respectively. In the same material, $0.2 \%$ of colonic carcinoma was found. One of the patients with ulcerative rectosigmoiditis had had rectal bleeding in the last 25 years because of hemorrhoids. Rectal bleeding, therefore, was not a new sign to her. Thus, $1.3 \%$ of patients with organic gastroenterological disease who required different treatments would be undiagnosed, following the previously mentioned recommendations. Patients with IBD would be treated with cortisone first and then with drugs targeting TNF- $\alpha$. Those patients with MC should be treated with budesnoid, which is the first-choice treatment. ${ }^{11}$ As for colorectal carcinoma, surgery and eventually chemotherapy are the available treatments. It is noteworthy that all the gastrointestinal organic diseases observed in our study occurred in IBS-D patients.

In a study with a limited number of patients (125 cases), flexible sigmoidoscopy barium enema or colonoscopy of patients who fulfilled the Rome I criteria for IBS identified no structural lesions, which changed the diagnosis of IBS. ${ }^{12}$ Others have reported a prevalence ranging from $0.4-1.9 \%$ of IBD in IBS patients. ${ }^{10,13-16}$ Several studies have found that MC can mistakenly be diagnosed as IBS. ${ }^{17-21}$ Furthermore, $1.5 \%$ of IBS patients have been found to suffer from MC. ${ }^{16}$

Another organic gastrointestinal disease has recently been the focus of attention, namely, celiac disease (CD) ${ }^{22-30}$ In patients with CD presenting in adulthood, minimal or atypical symptoms are encountered. The breadth of the spectrum of symptoms associated with IBS represents a potential for overlap between IBS and CD symptomatologies. Thus, individuals with CD presenting with relatively vague abdominal symptoms are at risk of being dismissed for having IBS. The situation becomes more complicated by the fact that in both CD and IBS patients, abdominal symptoms are triggered by ingesting wheat products. Whereas this can be explained in CD patients as a gluten allergy, one attributes this effect in IBS to the long sugar polymer, fructan, in wheat. In the same patient group investigated here, the prevalence of $\mathrm{CD}$ was $0.4 \% .{ }^{30}$ None of the patients with MC had CD.

It is conceivable to conclude from our findings and from earlier studies that symptombased diagnosis of IBS may lead to missing a number of other gastrointestinal disorders that require quite different management to that for IBS. Sigmoidoscopy in IBS patients might be insufficient, as a considerable number of MC cases may not be identified without mucosal biopsies from the right colon. ${ }^{20}$ Furthermore, performing a sigmoidoscopy would not exclude Crohn's disease lesions in the terminal ileum. Other blood tests seem to have a rather low sensitivity. ${ }^{31}$ Ileocolonoscopy is preferable, therefore, especially in IBS-D patients.

To perform an ileocolonoscopy with mucosal biopsies in IBS patients at first seems to add a greater economic burden to healthcare, which is already suffering from a lack of resources. In addition, it seems that resources for seriously ill patients would be provided to meet this task. IBS patients are already consuming a lot of the healthcare resources. It is estimated that 12 $14 \%$ of primary care patient visits and $28 \%$ of referrals to gastroenterologists are IBS patients, making this a more common reason for a visit to a physician than diabetes, hypertension, or asthma. ${ }^{32-34}$ Not only do IBS patients visit doctors more frequently but they also use more diagnostic tests, consume more medications, miss more workdays, have lower 
work productivity, are hospitalized more frequently, and consume more overall direct costs than those without IBS. ${ }^{35}$ The annual costs (both direct and indirect) in the USA to manage patients with IBS are estimated at 15-30 billion US dollars. ${ }^{36-38}$ Actually, most IBS patients have undergone colonoscopy once or several times. Unfortunately, the doctors that refer them and those who perform colonoscopy directly or indirectly act as if they expect no pathologic findings and that the examination is unnecessary. This does not reassure IBS patients and they seek another examination again and again. To perform an ileocolonoscopy would reassure IBS patients and prevent them from seeking a new examination. In conclusion, performing an ileocolonoscopy with mucosal biopsies in IBS patients would not increase the economic burden of this patient group on society but instead would use the existing resources effectively.

\section{References}

1. Thompson WG. A world view of IBS. In Irritable Bowel Syndrome: Diagnosis and Treatment. Camilleri M, Spiller R. eds. New York: Saunders, 2002, pp 17-26.

2. Everhart JE, Renault PF. Irritable bowel syndrome in office-based practice in the United States. Gastroenterology 1991;100:998-1005.

3. Drossman DA, Camilleri M, Mayer EA, Whitehead WE. AGA technical review on irritable bowel syndrome. Gastroenterology 2002;123:2108-31.

4. Longstreth GF, Thompson WG, Chey WD, et al. Functional bowel disorders. Gastroenterology 2006;130:1480-91.

5. Bercik P, Verdu EF, Collins SM. Is irritable bowel syndrome a low-grade inflammatory bowel disease? Gastroenterol Clin North Am 2005;34:235-45.

6. Burgman T, Clara I, Graff L, et al. The Manitoba inflammatory bowel disease. Cohort study: prolonged symptoms before diagnosis - how much is irritable bowel syndrome? Clin Gastroenterol Hepatol 2006;4:614-20.

7. El-Salhy M, Stenling R, Grimelius L. Peptidergic innervation and endocrine cells in the human liver. Scand J Gastroenterol 1993;28:809-15.

8. Pardi DS, Smyrk TC, Termaine WJ, Sandborn WJ. Microscopic colitis: a review. Am J Gastroenterol 2002;97:794802.

9. American College of Gastroenterology Task Force on Irritable Bowel Syndrome: An evidence-based position statement on the management of irritable bowel syndrome. Am J Gastroenterol 2009;104:S1-
35.

10. Tolliver BA, Herrera JL, DiPalma JA. Evaluation of patients who meet clinical criteria for irritable bowel syndrome. Am J Gastroenterol 1994;89:176-8.

11. van der Wounden EJ, Karrenbeld A, Kleibeuker JH, Dijkstra G. Microscopic colitis: an unfamiliar but treatable disease. Neth J Med 2009;67:41-5.

12. Francis CY, Duffy JN, Whorwell JA, Martin DF. Does routine abdominal ultrasound enhance diagnostic accuracy in irritable bowel syndrome? Am J Gastroenterol 1996;91:1348-50.

13. Hamm LR, Sorrells SC, Harding JP, et al. Additional investigations fail to alter the diagnosis of irritable bowel syndrome in subjects fulfilling the Rome criteria. Am J Gastroenterol 1999;94:1279-82.

14. Vanner SJ, Depew WT, Paterson WG, et al. Predictive values of the Rome criteria for diagnosing irritable bowel syndrome. Am J Gastroenterol 1999;94:2912-7.

15. MacIntosh DG, Thompson WG, Patel DG, Barr R, Guindi M. Is rectal biopsy necessary in irritable bowel syndrome? Am J Gastroenterol 1992;87:1407-9.

16. Chey WD, Nojkov B, Rubenstein JH, et. al. The yield of colonoscopy in patients with non-constipated irritable bowel syndrome: results from a prospective, controlled US trial. Am J Gastroenterol 2010;105:859-65.

17. Limsui D, Pardi DS, Camilleri M, et al. Symptomatic overlap between irritable bowel syndrome and microscopic colitis. Inflamm Bowel Dis 2007;13:175-81.

18. Barta Z, Mekkel G, Cspo J, et al. Microscopic colitis: a retrospective study of clinical presentation in 53 patients. World J Gastroenterol 2005;11:1351-5.

19. Madisch A, Bethke B, Stolte M, Miehlke S. Is there an association of microscopic colitis and irritable bowel syndrome? A subgroup analysis of placebo-controlled trial. World J Gastroenterol 2005;11:6409.

20. Kao KT, Pedraza BA, McClune AC, et al. Microscopic colitis: a large retrospective analysis from health maintenance organization experience. World J Gastroenterol 2009;15:3122-7.

21. Yantiss R, Odze R. Optimal approach to obtain mucosal biopsies for assessment of inflammatory disorders of the gastrointestinal tract. Am J Gastroenterol 2009; 104:774-83.

22. Fissora Cl, Koch KL. Symptom overlap and comorbidity of irritable bowel syndrome with other conditions. Curr Gastroenterol Rep 2005;7:264-71.

23. Sanders DS, Carter MJ, Hurlstone DP, et al. Association of adult coeliac disease with irritable bowel syndrome: a case-control study in patients fulfilling ROME II criteria referred to secondary care. Lancet
2001;358:1504-8.

24. Ziper RD, Patel S, Yahya KZ, Baisch DW, Monarch E. Presentations of adult celiac disease in nationwide patient support group. Dig Dis Sci 2003;48:761-4.

25. Wahnscaffe U, Ulrich R, Rieken E0, Sculzke JD. Celiac disease-like abnormalities in a subgroup of patients with irritable bowel syndrome. Gastroenterology 2001;121:1329-38.

26. Bottaro G, Calado F, Rotolo N, Spina M, Corazza GR. The clinical pattern of subclinical/silent celiac disease: an analysis on 1026 consecutive cases. Am J Gastroenterol 1999;94:691-6.

27. Green PHR, Stavropoulos SN, Panagi SG, et al. Characteristics of adult celiac disease in the USA: results of a national survey. Am J Gastroenterol 2001;96:126-31.

28. Makharia GK, Baba CS, Khadgawat R, et al. Celiac disease: variations of presentation in adults. Indian $\mathrm{J}$ Gastroenterol 2007;26:162-6.

29. Lo W, Sano K, Lebwohl B, Diamond B, Green PH. Changing presentation of adult celiac disease. Dig Dis Sci 2003;48:395-8.

30. El-Salhy M, Lomholt-Beck B, Gundersen D. The prevalence of celiac disease in patients with irritable bowel syndrome. Mol Med Rep 2011;4:403-5.

31. Schoepfer AM, Trummler M, Seeholzer P, Seibold-Schmid B, Seibold F. Discriminating IBD from IBS: comparison of the test performance of fecal markers, blood leukocytes, CRP and IBD antibodies. Inflamm Bowel Dis 2008;14:32-9.

32. Schuster MM. Defining and diagnosing irritable bowel syndrome. Am J Manag Care 2001;7:S246-51.

33. National Ambulatory Medical Care Survey. National Center for Health Statistics: NAMCS Description. Available from: http:// www.cdc.gov/nchs/about/major/ahcd/namcsdes.htm.

34. Mitchell CM, Drossman DA. Survey of AGA membership relating to patients with functional gastrointestinal disorders. Gastroenterology 1987;92:1282-4.

35. Spiegel BM. The burden of IBS: looking at metrics. Curr Gastroenterol Rep 2009;11: 265-9.

36. Talley NJ, Gabriel SE, Harmsen WS, Zinsmeister AR, Evans RW. Medical costs in community subjects with irritable bowel syndrome. Gastroenterology 1995;109: 1736-41.

37. American Gastroenterological Association. The Burden of Gastrointestinal Diseases. 2001.

38. Sandler RS, Everhart JE, Donowitz M, et al. The burden of selected digestive diseases in the United States. Gastroenterology 2002;122:1500-11. 